Nunt. Antiquus, Belo Horizonte, v. 14, n. 1, p. 133-157, 2018

\title{
Medea en las fronteras entre nos(otros)
}

\section{Medea at the Borders Between Us-Others}

\author{
Maria Fernanda Garbero \\ Universidade Federal Rural do Rio de Janeiro, Nova Iguaçu, Instituto Multidisciplinar, \\ Rio de Janeiro / Brasil \\ nandagarbero@gmail.com
}

\begin{abstract}
Resumen: Este artículo tiene como objetivo trazar una comparación entre el personaje Medea, de la tragedia griega de Eurípides, y tres piezas escritas en Argentina, Uruguay y Brasil. En contextos y tiempos completamente diversos de la Atenas de 431 a.C., es posible comprender la potencia que ese personaje sigue teniendo siempre que vuelve a los escenarios. La maternidad es el punto de encuentro elegido para esa lectura de las "Medeas", pero una maternidad que desde el principio trae consigo la cicatriz bárbara, desautorizando al sujeto como portador de una herencia. El tema del filicidio conecta esos textos a la tragedia, a pesar de la inscripción del carácter violento presente en Eurípides. En las "Medeas" de Latinoamérica, las muertes de los hijos adquieren un aspecto que se suma a la reivindicación de identidad, actualizando debates y heridas que históricamente se encuentran en los legados de la colonización.
\end{abstract}

Palabras-clave: maternidad; herencia; bárbaro; otro; reivindicación.

Abstract: This article compares the character Medea, from the tragedy by Euripides, and three plays written in Argentina, Uruguay and Brazil. In contexts and times completely different than those of the Athens of the 431st B.C.E. it is possible to understand the power that the character still has when it returns to the stage. The motherhood is the meeting point chosen for this reading of the "Medeas", but a motherhood that from the beginning brings with it the barbarian scar, disavowing the subject as the bearer of any heritage. The theme of the filicide connects the texts of these plays to that of the Greek tragedy, despite the ascription of violence present in the Euripidean character. In these "Medeas" of Latin America the murders can mean a claim of identity that proposes an update on the debates and wounds that historically are found in the legacies of the Colonization.

Keywords: Motherhood; Succession; Barbarian; Otherness; Claim. 


\author{
Mil nações \\ Moldaram minha cara \\ Minha voz \\ Uso pra dizer o que se cala \\ O meu país \\ É meu lugar de fala [...] \\ Nosso país \\ Nosso lugar de fala \\ "O que se cala", \\ en la voz de Elza Soares.
}

\title{
1 Del otro hacia nosotros (o más bien al revés)
}

¿Por qué todavía hablamos de Medea? ¿Qué tiene esa mujer que hace más de 2400 años nos asombra con su hecho imperdonable? ¿Es posible leer esa tragedia de Eurípides sin tomar partido? Entre muchas preguntas que nos planteamos ante la lectura de Medea, quizás la más constante ni siquiera esté entre las tres enunciadas ahora, sino en el ¿por qué? de su crimen, o mejor, ¿para qué?. Muchos pueden afirmar que se trata de una venganza provocada por el abandono de Jasón, pero la complejidad del personaje tramado por Eurípides parece decirnos más cosas, lo que hace que la perspectiva de una venganza - por más atroz que sea - quede como una parte del ¿por qué?.

Sabemos bien que la filicida que queda en nuestra memoria aparece con Eurípides, quien por primera vez cambia la noción del filicidio involuntario - sea como sacrificio a la diosa Hera, sea en el abandono de los hijos muertos apedreados por la gente de Corinto - y pone en escena un personaje plenamente consciente de lo que hace. La muerte de sus hijos en el texto trágico forma parte de un plan que se cobijará como su mejor venganza; un plan cuidado para ser irreversiblemente aniquilador, sin perderse en la noción reducida de reacción. Hay más.

Como vemos en el texto de Eurípides, su condición bárbara es lo que Jasón toma como justificación para distinguirla de las otras mujeres, mejor dicho, de las mujeres helénicas. Su destierro y las plagas portadas por los que no pertenecen a la Hélade, sumados al poder que Medea adquiere por su astucia con los corintios, sirven como ingredientes fundamentales a su combustión. Ya en el prólogo, la nodriza nos alerta 
de que esa mujer puede llegar a explotar, "pues violento es su ánimo y no tolerará ser menospreciado" (EURÍPIDES, Medea, v. 39-40).

La breve, aunque importante, referencia a su ánimo violento guía lo que sigue hasta el final, sosteniendo la tensión entre los personajes que comparten las escenas con Medea. Todo gira a su alrededor; alrededor de su potencia para engendrar las vidas y las muertes que se encuentran en los mitos y, en la tragedia, se suman al filicidio.

Es teniendo en cuenta tal potencia engendradora, aquí pensada en la representación de una maternidad bárbara, como este trabajo propone la lectura de tres maneras distintas de mirar la tragedia a través de la recreación del mito, en contextos y tiempos bastante lejanos de aquella Atenas de 431 a.C. Desde el sur, o sea, desde las orillas del Río de la Plata hasta los escenarios de Río de Janeiro, pretendemos trazar algunos caminos que nuestras Medeas parecen seguir cuando escritas, presentadas y, por que no, paridas en otras fronteras más cercanas. La Cólquida de la antigüedad cede el lugar a las tierras gauchas, a la memoria de las violencias resultantes de la colonización española y a las calles de grandes ciudades sin nombre, donde la condición del exiliado, pensada en la contemporaneidad, puede llegar a ser una constante.

Comprender esas dimensiones diversas que Medea logra en tales contextos, además de acercarnos, aunque simbólicamente, a nuestros vecinos argentinos y uruguayos, permite una articulación que cuestiona las muchas identidades encerradas en lo que consideramos argentinos y uruguayos, poniéndonos como interlocutores de ese otro que, quitando la proximidad geográfica, traduce herencias opacas, distantes e históricamente borradas. Como punto de partida, trataremos de las piezas La frontera (Argentina, 1960), de David Cureses, Medea del Olimar (Uruguay, 2009), de Mariana Percovich, e Mata teu pai (Brasil, 2016), de Grace Passô. Alejadas de Corinto, sin su Cólquida y no más en Atenas, las protagonistas dan vida - y muerte - desde la pampa, desde los rincones de un pueblecito rural uruguayo y desde alguna ciudad (des) ubicada en un país donde, en portugués, Medea gesta otras maneras de hablar y ser oída. 


\section{Las fronteras}

En El miedo a los bárbaros, Tzvetan Todorov en determinado momento nos propone una diferenciación entre dos sentidos del vocablo bárbaro. Tras discurrir sobre la comprensión griega de ese otro al extremo, situando en la guerra contra los persas un principio para el uso del término, Todorov habla de una tensión entre un significado relativo, correspondiente al extranjero incomprensible por cuestiones lingüísticas, y un absoluto, que históricamente provendrá de la extrañeza frente a lenguas desconocidas, basada en el contacto de los griegos con los que no hablaban griego, y alargándose a partir del siglo XV cuando empiezan los viajes y las clasificaciones de los pueblos dominados por los europeos. En ese sentido absoluto se enfatiza la noción de 'cruel', clave para las empresas de catequización y anulación de las lenguas indígenas como etapas de la civilización, cuyo punto de referencia estaba en la cultura cristiana, blanca y, por supuesto, europea. Como ejemplo, tenemos la llegada de los españoles y portugueses a América y el exterminio indígena que se produjo como sistematización de un "plan civilizacional" por la pluma, la cruz y la espada.

En la problematización histórica de Todorov, el civilizado inicialmente se opone a los bárbaros por ser "en todo momento y en todo lugar, el que sabe reconocer plenamente la humanidad de los otros" (TODOROV, 2014, p. 39). Con una mirada (rápida) hacia nuestra historia, tal idea parece más un chiste de mal gusto que propiamente una postura de reconocimiento. En líneas generales, los hechos de los colonizadores traducen evocaciones de barbarie bastante salvajes - tomando prestada una palabra cara a los que aquí llegaron - y en ese sentido Todorov nos alerta, anticipando su discusión sobre los contextos actuales entre los países árabes y el occidente, al decir que la misma facultad que algunos primatólogos encuentran para narrar al "civilizado", enfocada en la compasión, es también la que "nos empuja a torturar al otro o a participar en un genocidio" (2014, p. 39).

Por lo tanto, delante de las implicaciones contenidas en tales términos y de lo que sucedió en Latinoamérica, es imposible pensarnos desde aquí sin tener en cuenta una violencia que también forma parte de 
nosotros, y "formar parte" ahora reivindica saltar la frontera y comprender - o al menos intentarlo - las violencias concretas y simbólicas que todavía apuntan para quienes son los potenciales "otros" en la exclusión: los sujetos desautorizados y apartados de los "sistemas simbólicos", concepto importante de Pierre Bourdieu para nuestra discusión, pues permite entender, a su vez, a los personajes que encontramos en la Medea de Eurípides y en las piezas de nuestro recorte:

los sistemas simbólicos cumplen la función política de instrumentos de imposición o de legitimación de la dominación, que cumplen para garantizar la dominación de una clase sobre otra (violencia simbólica) dando refuerzo de su propia fuerza a las relaciones de fuerza que las fundamentan y contribuyendo, de esa manera, según la expresión de Weber, a la domesticación de los dominados. (BOURDIEU, 1989, p. 11). ${ }^{1}$

Tomadas las debidas proporciones, cuando Jasón rechaza la ira de Medea, antes de la muerte de los niños, se basa en lo que representa en aquel contexto su condición de bárbara, como ya hemos mencionado, y es así como esos sistemas simbólicos emergen en la tragedia:

Sin embargo, por haberme salvado, has recibido más de lo que diste, como voy a explicar. En primer lugar, habitas una tierra helena en vez de un territorio bárbaro, has aprendido justicia y a servirte de leyes, sin favorecer la violencia. Todos los helenos se enteraron de que eres sabia y adquiriste renombre. Si habitaras en remotos confines, no existiría tu prestigio. (EURÍPIDES, Medea, v. 532-541).

\footnotetext{
1 “Os sistemas simbólicos cumprem a função política de instrumentos de imposição ou de legitimação da dominação, que cumprem para assegurar a dominação de uma classe sobre a outra (violência simbólica) dando reforço da sua própria força às relações de força que as fundamentam e contribuindo, assim, segundo a expressão de Weber, para a domesticação dos dominados". La traducción de los textos no publicados en español es de nuestra autoría (los datos completos de las ediciones se encuentran en las referencias).
} 
Además de situarla a través de una memoria que regresa simbólicamente de un dentro-fuera en el momento de la discusión, se invoca su actual espacio para la reubicación de una pertenencia no autorizada, es decir, de una "estadía" condicionada. Al confrontar la tierra

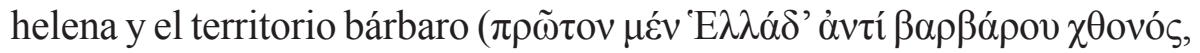
v. 536), Jasón toma como parte de su argumento un elemento que para él pertenece a los griegos: el renombre, lo que corresponde a una distinción que radicalmente se contrapone a la imposibilidad de su origen bárbara. Medea, así, no solamente deja de habitar una tierra inhóspita, como será la que tiene fama ( $\delta o ́ \xi \alpha v$ ह̌ $\chi \chi \varepsilon \zeta$, v. 540). Lo simbólico y lo concreto, en ese momento, se suman al entendimiento de un espacio donde Medea ve su vida en manos de los designios de los que tienen el poder sobre la pólis, con sus leyes que tampoco le pertenecen por derecho, dentro de esa comprensión.

Su carácter bárbaro, ya anunciado por la nodriza como "violento" desde el comienzo, queda en estado de latencia durante toda la tragedia, y con el asesinato de los hijos Jasón confirma la crueldad y la monstruosidad como constituyentes indisociables de Medea, recuperando una memoria aún más profunda y antigua sobre ella, también presente en las versiones del mito donde hay otros crímenes que la religan con su tierra. La cita siguiente, aunque demasiado extensa, es interesante por congregar, en forma de conclusión, el trazo bárbaro y todo lo que eso es capaz de dejar como huella/legado:

¡Ojalá te mueras! Y yo cuerdo estoy ahora, pero entonces no lo estaba, cuando, desde tu palacio y de una tierra extranjera, te conducía hacia un hogar heleno, horrible desgracia, traidora a tu padre y al país que te había criado. Los dioses han lanzado contra mí tu espíritu vengador, pues tras dar muerte a tu hermano cabe el hogar, subiste la nave Argo de hermosa popa. Por tal crimen comenzaste. Después de casarte con ese hombre que te habla y darme hijos, por culpa de un lecho y una esposa, los aniquilaste. No existe mujer griega que jamás se hubiera atrevido a eso, y, por delante de ellas, creía oportuno casarme 
contigo, matrimonio odioso y fatal para mí, leona, que no mujer, pues tienes una naturaleza más salvaje que la tirrénica Escila. (EURÍPIDES, Medea, v. 1329-1343).

Además de lo que podemos ver en ese momento de la tragedia, nos llama la atención una de las formas elegidas por el traductor Juan Antonio López Férez, en la edición de Cátedra, para componer la noción de "casa bárbara" desde donde emigra Medea, diferenciándose de lo que

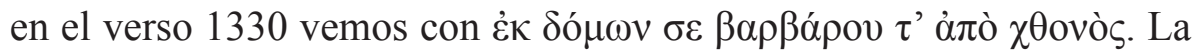
traducción por "tierra extranjera" para un lector de la actualidad puede referirse, de hecho, a aquel que proviene de un país diferente. Sin embargo, deja en suspenso justamente lo que marca y, por qué no, limita a ese otro en un sistema que no le permite tener los mismos ejes de reconocimiento que aquellos que tienen "derecho de suelo". Completamente diferente del xénos, el extranjero como huésped de otra ciudad que hablaba griego y compartía los mismos sistemas simbólicos comprendidos en los hábitos culturales de distinción frente a los bárbaros, Medea es la leona que se asemeja a un monstruo mítico temible y sin forma humana. La pérdida de su humanidad, con la muerte de los hijos, hace que se concretice la primicia del peligro de los que, sin ley y sin justicia, como le dijo Jasón en su primer embate, solo pueden vivir entregados a la violencia.

La condición animal de esa Medea-leona es muy importante en la comparación entre las piezas que forman parte de ese diálogo con Eurípides. De maneras diversas, por cuestiones contextuales, vemos la animalización como argumento presente en las voces de los que comparten los conflictos con las Medeas de nuestro recorte, sea directamente o a través de la memoria de la protagonista. Cuando tomamos, por ejemplo, el drama argentino La frontera (1960), de David Cureses, cuyo contexto está basado en la Conquista del Desierto (1878), comandada por el entonces Ministro de Guerra, el general Julio Roca (y el más grande responsable del genocidio de los pueblos indígenas que vivían en la región de la Patagonia y La Pampa), a la idea del indio-bárbaro se le añade una discusión histórica: el conflicto entre civilización y barbarie. 
Con respecto a lo que encontramos acerca de tal embate, en 1845 tenemos la publicación de Facundo, de Domingo Faustino Sarmiento, que posteriormente será presidente de Argentina (cuatro años antes de Julio Roca) y a quien hasta hoy se le reconoce un rol de destaque en la constitución de la enseñanza pública en ese país. Sobre esa obra de gran relevancia para la comprensión de las tensiones políticas internas entre Unitarios y Federales, nos interesa cómo el bárbaro aparece en las herencias indígenas $\mathrm{y}$, por extensión, en las conformaciones históricas del gaucho.

La trama política argentina es bastante compleja y no nos cabe reducirla a una discusión que la recupere a través de un interés puntual. Pero aclarar algunas divergencias entre Sarmiento y Juan Manuel de Rosas, a través de la voz de Sarmiento, tiene relación con lo que nos dice Todorov sobre el bárbaro absoluto, es decir, cruel y violento, culpable por los atrasos civilizacionales, según el autor de Facundo. Ya en las primeras páginas, el caudillo Rosas - su gran opositor y contemporáneo de otro caudillo destacado, Facundo Quiroga, que, aunque lleve su nombre en el título, sirve para que Sarmiento hable de Rosas - es presentado de la siguiente manera:

Un día vendrá, al fin, que lo resuelvan, y el Esfinge Argentino, mitad mujer por lo cobarde, mitad tigre por lo sanguinario, morirá a sus plantas, dando a la Tebas del Plata el rango elevado que le toca entre las naciones del Nuevo Mundo. (SARMIENTO, 1999, p. 26).

La referencia a imágenes clásicas, además de formar parte de un plan cultural en el que Buenos Aires se equipara a la mítica Tebas, trae la ausencia de la condición humana como un rasgo que caracteriza a los que representan la barbarie. Su emblemática frase acerca de Rosas, "mitad tigre por lo sanguinario, mitad mujer por lo cobarde" recupera el monstruo híbrido derrocado por Edipo al llegar a Tebas y libertar la ciudad de su maldición, confirmando la potencia animalesca de los que impiden el desarrollo de un "Nuevo Mundo" de base ilustrada, europea (más específicamente, francesa). Eso refuerza los rasgos del atraso que son 
retomados durante toda la obra como una herencia de la independencia: "Había antes de 1810 en la republica Argentina dos sociedades diversas: la una española europea, culta; y la otra bárbara, americana, casi indígena" (SARMIENTO, 1999, p. 81).

Según esa noción, el bárbaro pierde su trazo foráneo cuando entran en juego los que van a escribir las narrativas históricas. $\mathrm{Su}$ "enfermedad" adquiere una potencia endógena, propicia a la dominación, y el indio es el que mejor servirá para expresarla, por no pertenecer a los sistemas simbólicos de los colonizadores. Tras el genocidio de los pueblos indígenas, que todavía persisten y conectan hediondamente nuestros países, el bárbaro sigue siendo descripto por su potencia híbrida, es decir: a través de otros cuerpos e identidades desautorizados, excluidos de los proyectos nacionales. Sin reconocimiento de legitimidad, es como si su cuerpo estuviera a disposición de un exterminio autorizado socialmente.

Con razón, una Medea posible, capaz de actualizar la potencia bárbara que vemos en Eurípides, solo tiene sentido cuando recupera quienes pueden ser nuestros bárbaros en las narrativas oficiales. Si en Cureses es una india cuyo nombre está en una nominación ajena, producto del contacto con los cristianos, "Bárbara, me dicen... así me pusieron hace mucho... otros frailes en la tribu" (CURESES, 1960, p. 64), es porque encontramos en la creación ficcional un tema de circulación fácilmente reconocible, sobre todo cuando nos acordamos de Facundo. El enredo que se pasa en un pueblo indígena de la pampa, en el interior de Argentina, rescata además un espacio donde se trabaron muchas luchas, como leemos en Sarmiento, entre los Federales y los Unitarios, siendo un territorio de predominancia de gauchos y caudillos.

Ahora Jasón forma parte de la Conquista del Desierto al lado del Coronel Ordoñez, ambos representantes de la patria, cristianos y blancos. Juntos, deciden expulsar a Bárbara de su tierra, tomando a sus hijos y armando el casamiento entre Jasón y la hija del Coronel, como manera de anular "los diez años viviendo a lo indio" (CURESES, 1960, p. 39), según las palabras de Jasón. El texto comienza diez años después de Bárbara haber traicionado a su padre, el cacique Coliqueo, cuando Jasón había 
llegado a su pueblo para luchar contra los indígenas que allí vivían. ${ }^{2}$ Así como en los mitos de los Argonautas en la Cólquida, la supervivencia y el posterior asentamiento de Jasón se deben al encuentro con esa mujer que, como Medea o Bárbara, reescribirán en sus cuerpos la idea de frontera. La oposición con el bárbaro, en Cureses, aparece en lo que se proyecta en el imaginario de los militares acerca de la dicotomía civilización $\mathrm{x}$ barbarie, incluso marcado en el habla, como vemos en ese diálogo entre Bárbara y Coronel Ordoñez, cuando este llega para decirle que se vaya:

C. ORDOÑEZ. - Soy el coronel Ordóñez ... Nuevo comandante del Fortín "Las Mulitas" ... soldado de la conquista del desierto ... hombre de la patria ...

BARBARA. - (Lo mira altanera y luego responde con todo el orgullo de su raza.) Y io soy la hija del cacique Coliqueo ... dueña de tuito lo que loj ojos alcanzan a ver pa el sur y pa el norte ... y de tuito lo que los ojos no ven pero el corazón andivina ...

\footnotetext{
${ }^{2}$ Infelizmente, aunque David Cureses haya sido en los años 60 un autor premiado y reconocido, sus obras teatrales están agotadas y ni siquiera en la Biblioteca Nacional Argentina es posible encontrarlas por completo. Por un interés proveniente de la lectura de Otras Medeas: nuevas aportaciones al estudio literario de Medea (Granada, 2007), de Andrés Pociña, supe de la publicación de La frontera y por medio de una colega de la Universidad de la Ciudad de Nueva York (CUNY), pude obtener una copia del texto, ya que en Argentina se hacía imposible. En el momento, preparo la edición crítica bilingüe con la traducción de la pieza al portugués. Por motivos que todavía no nos fue posible comprender, sus obras cayeron en el olvido; las referencias a lo que hizo son básicamente inexistentes, excepto por la gente que trabajó con él en el teatro y que pude conocer a partir de la investigación en Buenos Aires y Adrogué, donde el dramaturgo vivió hasta su muerte en 2006. Todo lo que conseguimos saber sobre el contexto de $L a$ frontera son datos y fechas que aparecen en el primer acto y que, cuando comparadas históricamente, hacen conexión con la Conquista del Desierto (1878). Con respecto al tiempo de la llegada de Jasón, una década antes, la referencia puede ser a lo que se sucedió a la ley 215, sancionada en 1867 en el gobierno de Bartolomé Mitre. En términos generales, la ley permitió una expedición general contra grupos indígenas opositores al sometimiento de las autoridades argentinas. Tales grupos deberían ocupar una nueva línea de frontera, formada a partir de la expulsión de sus tierras. El cacique Coliqueo aparece en los documentos históricos argentinos como jefe de una tribu mapuche que vivía en la región de Los Toldos, provincia de Buenos Aires.
} 
C. ORDOÑEZ. - Hacia el Norte, estamos nosotros, la civilización que avanza ...

BARBARA. - Malos pasos trae la civilización que acorrala al indio hasta ahogarlo ...

C. ORDOÑEZ. - (Un poco picado.) Se resisten a ser gente ... sólo queremos enseñarles.

BARBARA. - ¿Qué cosa? ... ¿A ser crestianos? ...

C. ORDOÑEZ. - A saber de Dios ... y de la patria ... de los deberes y obligaciones del hombre, de la justicia y el trabajo ... Queremos levantarlos hasta nosotros ... vernos todos al mismo nivel, ser iguales ... hermanos como cuadra a los nacidos bajo un mismo cielo ... sin distingo de raza, ni de sangre ...

BARBARA. - (Segura pero conteniéndose, pronta a saltar.) Muy lindas sus palabras, coronel ... pero entre ustedes y nosotros hay levantada una paré de sangre ... que se hace muy difícil saltar... (CURESES, 1960, p. 18. Grifo nuestro).

Las violencias de la "Conquista" son retomadas en las dos voces, lo que hace que Bárbara asuma lo que entendemos como una portademanda de su tiempo y su espacio. En ese sentido, la narrativa histórica se cuestiona, revisita y revisa desde la ficción, y la historia que podemos oír se construye en el sentido benjaminiano del contrapelo.

En comparación con la literatura que vemos en el siglo XIX brasileño, por ejemplo, en la que el indio alencariano se basa en el buen salvaje de Rousseau, soportando el sacrificio como parte de su carácter "apto" para la colonización, la protagonista de Cureses, curiosamente, se aleja en el mismo punto en que se la conecta a Iracema: ambas habrían traicionado a su tribu; ambas hicieron del colonizador su amante. Sin embargo, mientras que es necesario la muerte de Iracema para que nazca el hombre americano, "el hijo del dolor" Moacir, casi cien años después vemos que los que tienen que morir para que otra historia sea contada son los hijos de Bárbara, pues el filicidio se torna la manera de impedir que el proyecto de anulación identitaria de los indígenas persista. 
La frontera está puesta. Es por Bárbara que sabemos que eso se debe a la raza, a la sangre y, con la llegada de Ordoñez, comprendemos que las fronteras jamás serán iguales para todos:

C. ORDOÑEZ. - (Seguro.) Tendrás que partir sola...

BARBARA. - Con mi hombre dije...

C. ORDOÑEZ. - No pienses en él...

BARBARA. - ¿Por qué?... Ni aunque juera muerta, metida en un pozo dejaría de pensar en él...

C. ORDOÑEZ. - Tendrás que hacerlo...

BARBARA. - (Comienza a desbordar su fuerza.) Pero, ¿quién es usté pa exigir tanto?...

C. ORDOÑEZ. - (El diálogo se hace más cortante.) Ya te lo dije... aquí soy como el dueño y señor... Dicto las leyes de esta avanzada en el desierto y mis leyes deben respetarse... y yo ordeno, me entiendes, ordeno... que partas a tus tierras antes de que despunte el nuevo día...

BARBARA. - Que me acompañe Jasón, él me trajo aquí... Que me lleve a mis tolderías... de donde me sacó... a los míos, qu'él me hizo traicionar...

C. ORDOÑEZ. - Sólo vos levantaste a tu pueblo contra tu padre... ¡no merecés compasión!... (CURESES, 1960, p. 27).

La memoria de la potencia bárbara, como ya lo hiciera Jasón de Eurípides, regresa con la acusación de la traición previa a su padre y la prerrogativa de aniquilamiento se rehace a partir de un hecho fuera del tiempo. La muerte de los niños, como cúspide del estado de barbaridad, oscila con Cureses entre el desespero y la reivindicación de los hijos de Bárbara como sus hijos, dándole el derecho de decidir sobre qué tipo de vida pueden tener aquellos que tienen sus rasgos de identidad anulados. En cierta medida, el autor intenta, como hicieran otros escritores, invertir la noción de barbarie, componiendo el personaje que tiene de su lado la presuposición patriótica como el sujeto de la violencia.

Fuera del contexto de la tomada de las tierras por el ejército de la patria, lo que no deja de traer consigo la marca que la masacre de la 
colonización siguió produciendo, el bárbaro y su cuerpo cambiante se dirigen hacia las herencias de las mezclas, sin perder en su condición social el rasgo distintivo que lo habilita a la exclusión. El interior, la zona rural y los espacios alejados de aquella Buenos Aires-Tebana ideada por Sarmiento quedan en el imaginario como territorios donde la civilización aún no se concretizó de forma completa. Es la tierra del gaucho. En las extensiones semánticas que se le añaden al bárbaro, es en esos espacios donde puede emerger la barbarie con su sentido radical y endógeno. Por tanto, la transformación del territorio geográfico en escenario de ficción, además de inscribir en esa perspectiva un relato a contrapelo, recrea las voces de los ninguneados y apartados de los derechos garantizados por un estado del bienestar social.

Es en ese espacio rural con sus signos de alejamiento donde surge la protagonista de Medea del Olimar (2009), de la dramaturga uruguaya Mariana Percovich. Según Percovich, en su pagina personal, el enredo que sostiene la puesta en escena se da a partir de un hecho ocurrido en el interior del país, una crónica policial:

En el año 2008 al regresar del viaje a Francia, descubro en la crónica policial uruguaya un caso real en el medio rural. Una madre mata en el campo a su hija pequeña, lo que genera la ira en los lectores de los diarios que comienzan a reaccionar casi de una manera griega. Muchos claman por linchar a esa madre, otros prefieren que no se hable del crimen, "demasiado horrendo". (PERCOVICH, 2010, s.p.).

Uniendo ese hecho a las tragedias de Eurípides, Séneca y a la recreación del mito en Medeamaterial (1992) de Heiner Müller, Percovich mantiene algunas referencias que retoman el texto griego, pero desde la divulgación de la pieza la autora ya alerta que el público se encontrará con una "Medea sin furor", concepto fundamental del personaje senequiano. La madre del Olimar no mimetizará el exceso, la ira o un rasgo cruel. Lo bárbaro de su hecho representa una condición que a lo largo del texto está presente en la composición de la mujer-vaca, o sea, en una condición femenina bajo la sumisión impuesta socialmente. En ese sentido el 
texto de Percovich se aproxima al de Müller (y, por qué no, Cureses), al tratar de la venganza como denuncia de los abusos resultantes de las obligaciones históricas que se engendran en ese cuerpo, a partir de su deber de procreación en un orden jerárquico masculino.

En el cartel de estreno del espectáculo en 2009, el pequeño texto ratifica la perspectiva de una historia extraída de lo real, desde un punto de vista donde la voz de esa mujer oriental - como son llamados los que nacen en el Uruguay, cuyo nombre oficial es República Oriental del Uruguay - se hace como una versión posible de la narración de un crimen que no permite perdón social, sobre el cual no se aceptan justificaciones más allá del juicio de barbaridad.

FIGURA 1 - Cartel de la pieza

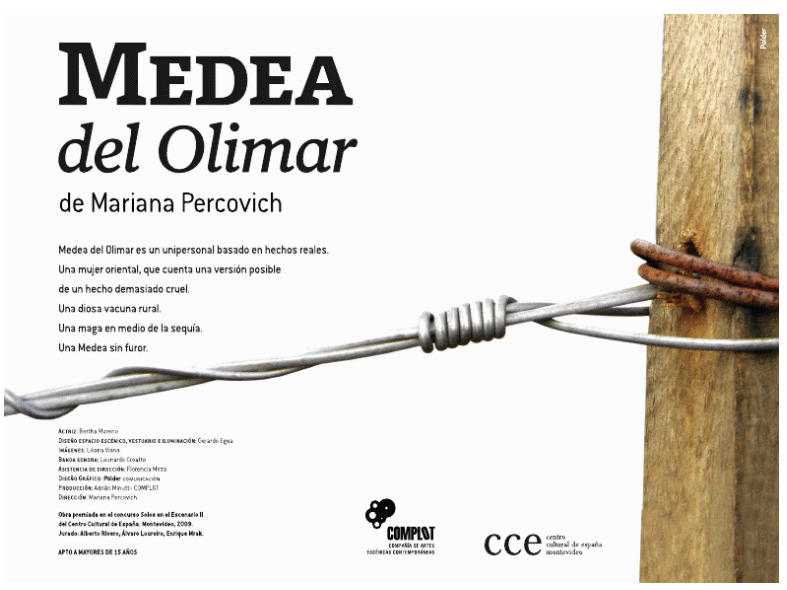

Fuente: $<$ http://marianapercovich8.blogspot.com.br/ search?updated-max=2010-08-26T17:01:00-07:00> .

La pieza tuvo mucha repercusión en Latinoamérica, incluso fue presentada en 2009 en la inauguración de la Escuela Municipal de Teatro de San Pablo. El drama es un monólogo, lo que es fundamental para escuchar lo que puede decir esa mujer y que fuera de la ficción no le sería permitido. Los personajes que comparten la historia son presentados por esa voz que desde el comienzo reivindica una comprensión de los espacios simbólicos que se inscriben en el cuerpo-mujer-rural-desechable: 
Yo soy Medea

La vaca oriental

Triste y gorda vaca del Olimar

Despeinada

Con el cerebro frito por los electroshock del hospital

Soy como esa vaca que pasta en la ruta,

comiendo el pasto que quedó

después del paso de Seca

Araña autóctona

Araña domiciliaria y rural

Vivo detrás de los muebles

Me muevo poco

Y solo ataco en la cama revuelta

Si me molestan .

Vaca

que parió hace seis años

un potrillo raquítico

una yegüita temblorosa y flaca

con las costillas marcadas en los flancos de un lomo

marrón,

una potrilla joven y nerviosa

que me mira con ojos negros y busca mis tetas cansadas

y caídas

Milagros me dicen que se llama.

Me lo dice Jasón

y yo miro sin entender

Milagro de parir, me dice la nodriza

y yo miro con asco a ese montón de huesitos todavía blandos y mojados que acaba de salir de mí

Jasón el hombre al que seguí

Contra mi padre y mi madre

Por que quise 
Hoy es un pastor roñoso de ovejas que mete los dedos en la lana sucia

Y se los chupa

Jasón

Que toma caña con Seca

Jasón que no habla

Nunca

Jasón, pastor de almas para Seca

Medea del olimar

Soy una asesina triste

Obesa y vacía

como una vaca en un tajamar inútil que busca en el fondo de barro y pasto lo que Seca dejó a su paso

Vaca

(PERCOVICH, 2009, p. 3-5. Grifo nuestro). ${ }^{3}$

Las analogías que se hacen con los animales recrean una Medea fabular en su correspondencia alegórica, trazando una aproximación entre las características de dichos animales y los personajes, como vemos en "la vaca" que pasta y da la leche; "la araña" que se esconde en el rincón y ataca cuando acosada; "el potrillo, la yegüita y la potrilla" como un solo personaje raquítico parido por esa vaca; y en "las ovejas" como imagen de las mujeres pastoreadas por un Jasón que mantiene su poder en el orden patriarcal.

Híbridos de lo humano y lo animal, la Medea del Olimar y su hija/cría recuperan la perspectiva de un legado donde la inscripción en lo monstruoso las distingue de los hombres como Jasón y Seca. Con respecto a ese personaje, la psicoanalista Marta Labraga, en artículo para la página personal de Mariana Percovich, propone una lectura de los elementos imbricados en su composición multifacética y polisémica, al argumentar que Seca sea al mismo tiempo:

${ }^{3}$ El texto fue gentilmente cedido por la autora para integrar el presente artículo. 
'La' Seca que se come las tierras y las cosechas [...], la locura que calcina estos cerebros que son después "reparados" por los choques eléctricos hasta la quema de todo pensamiento, el 'dueño de todo', el dueño de la tierra y de los seres, el Macho de la horda que circularmente coge a las hembras, les hace sus 'milagros' y después se los reapropia [...]. (LABRAGA, 2010, s.p.).

Seca y Jasón permanecen en el centro del poder masculino, sin embargo es desde la caída moral como se los nombra; sus presencias, que solo se hacen posibles por la voz de Medea, representan a los responsables de un orden de sometimiento, en el cual a las mujeres solo les quedan los espacios destinado a los animales - el pasto o el rincón de una araña - o a los locos. La parte humana de ese monstruo híbrido debe ser controlada, y para eso servirán los choques eléctricos que, además de calcinar el cerebro, deben aniquilar la parte humana del monstruo, es decir: su potencia pensante. Una vez más, mito y recreación se encuentran en la propuesta de revisión, recuperando un personaje que elabora, piensa, razona, como vemos en el propio nombre de Medea y su posible relación con el verbo médomai, que en griego puede significar 'pensar', 'cuidar', 'elaborar' y 'planear', remitiendo aún a la noción de 'buen consejo'.

No por casualidad, ese lugar ofrecido a una Medea que habla y reivindica una mirada hacia las violencias históricas impuestas a las mujeres, desde su posición en un orden social sin igualdad de géneros y partiendo de una maternidad problemática, se muestra en la autoría femenina. La pieza de Percovich nos hace recordar lo que dice Gayatri Spivak, en el capítulo "Femenismo y teoría crítica", de su libro En otras palabras, en otros mundos (2013), al afirmar que "el esencialismo es una trampa" (SPIVAK, 2013, p. 156), refiriéndose a los estudios feministas de base positivista que, a través de la literatura, intentaron hablar del cuerpo de la maternidad como un cuerpo de poder. Si lo ubicamos en ese escenario, una pregunta al mismo tiempo obvia y fundamental merece ser hecha: ¿de dónde parte tal poder? Si a la maternidad se la considera como un índice del poder en la generación de nuevos seres, el hombre sigue dictando los límites y posibilidades del cuerpo-mujer, y los hijos 
siguen siendo signos de su poder en la sociedad, sobre todo teniendo en cuenta que, recuperando lo que propone Spivak en su discusión sobre la reproducción dentro de una problemática marxista, "el hombre retiene los derechos de propiedad legal sobre el producto del cuerpo de una mujer" (SPIVAK, 2013, p. 142).

Por lo tanto, además de revolver y cuestionar tal esencialismo, clavando un dardo en la maternidad a partir de la madre que mira hacia su propia condición, Percovich parece rescatar en su texto el intenso momento en el que la Medea euripidiana pone en escena la oposición entre los deberes de las mujeres y los derechos de los hombres, como dos sendas incompatibles y por siempre paralelas, al decir:

De todos los seres animados y dotados de pensamiento las mujeres somos el más desdichado. Pues, en primer lugar, tenemos que comprar un marido con excesivo gasto de dinero y conseguir un dueño de nuestro cuerpo, pues ésta es una desgracia más dolorosa aún. [...] Dicen que nosotras pasamos en nuestros hogares una vida carente de peligros, mientras ellos combaten con la lanza. Pero razonan con torpeza. Que tres veces preferiría yo permanecer junto al escudo, antes de tener un solo parto. (EURÍPIDES, Medea, v. 231234 ; 248-253).

Más allá de la referencia directa a la tragedia, la recepción del personaje Medea en el texto de Percovich parece rescatar esa voz que surge en aquella Atenas del siglo V a.C. ya como un problema, aunque sea un problema planteado por la bárbara y, por extensión, sin cualquier contexto histórico viable a lo que hoy podemos identificar en muchos de los debates feministas que se disponen a leer la maternidad desde su rasgo compulsorio; no más basado en el esencialismo y en el mito del amor materno (BADINTER, 1985).

La madre-vaca que solo puede parir un potrillo raquítico destinado a la muerte, cuando asume su forma humana migra del pasto hacia el manicomio, espacio-cárcel donde su cuerpo-cerebro precisa ser quemado para aniquilar la parte humana responsable de la muerte 
de su hija y discapacitada del ejercicio de la maternidad socialmente aceptada. En Medea del Olimar vemos esa transgresión sumarse a la desconstrucción de un cuerpo históricamente obligado a la reproducción. Afuera de las fronteras que delimitan simbólicamente la propia figura de la madre en una sociedad judeocristiana, la pieza, al referirse a un hecho real, hace su crítica a partir de una mujer de carne y hueso que mata a su hija de seis años y, como suele ocurrir en los casos de infanticidios por parte de la madre, será juzgada duramente por toda la sociedad que, igual que sucede con las Erinias de los mitos griegos, nunca jamás la perdonará. Dejarle hablar, aunque sea (o porque sea) en la representación teatral, es sacarla de su comprensión social monstruosa y devolverla simbólicamente a su porción humana, constituciones alegóricamente presentes en la composición de la mujer-bicho que pare bichos no aptos para la vida.

La aptitud para la vida en un contexto basado en las leyes y en oposición a la violencia debe contraponerse a la barbarie, luego, el filicidio se vuelve el crimen bárbaro por antonomasia. Pero aún en relación con tal aptitud, otra pregunta puede aparecer cuando nos cuestionamos acerca de qué vida se habla cuando los herederos de esas mujeres híbridas también llevan en su destino el rechazo de su poder humano. Si hablar del término humano es demasiado extenso, hablemos de su correlación con las leyes y, así, hablemos de los derechos, como metonimias para pensarlo cuando el sujeto de la discusión es una mujer. ¿Hablaremos de los derechos de las mujeres que todavía tienen sus cuerpos bajo el control de leyes que no les permiten decidir sobre su cuerpo? Entonces, sin riesgo de anacronismos, lo que nos dice la trágica Medea en los versos 250-253 es extremadamente actual cuando nos ubicamos en la frontera brasileña y vemos nuestros cuerpos dispuestos en las narrativas que impiden, por ejemplo, una discusión seria acerca de la despenalización del aborto, hecho que para muchos brasileños es un crimen bárbaro.

La vida como algo mucho más amplio que la existencia y el derecho de decisión son dos de los temas que vemos en la voz de Medea de Mata teu pai (2016), de Grace Passô. Una vez más, como porta-demanda de su tiempo, la princesa de la Cólquida regresa desde 
su discusión sobre la maternidad, ahora poniendo en escena cuestiones como el racismo, la misoginia y el odio a los pobres e inmigrantes en un Brasil cada día más reaccionario que nos toca vivir. En este punto, la fibra materna (BADINTER, 2011) se hace desde la interrupción del destino como deinós: la muerte como acto de amor capaz de cambiar la senda terrible de las herederas de un camino ya trazado por la sumisión femenina.

Como las protagonistas de La frontera y Medea del Olimar, la de Passô no mata por venganza. La unión de un estado febril con las doce señoras que la acompañan, en una reactualización del coro griego, hacen que el público conozca de a poco un nuevo personaje, capaz de entresacar de los mitos la potencia del verbo médomai en una Medea dispuesta a cuidar a los otros, o mejor, a las otras que como ella son obligadas a aceptar la frontera como línea intraspasable en la demarcación de sus diferencias. Así como en la pieza de Percovich, estamos ante un monólogo, pero desde un habla que reivindica al otro como interlocutor y participante en sus debates, aunque el espectáculo no sea interactivo. Por muchos momentos, ella retóricamente pregunta a su público si la está escuchando, para después reescribir su historia con la frase grafiteada en el escenario en letras mayúsculas: "SOU DO TAMANHO DO AMOR", ${ }^{4}$ otra vez presentándose sin el furor senequiano y desnuda de la venganza gestada por la Medea de Eurípides. Su grito-grafiti genera otra dimensión sobre ese cuerpo y su incómodo se alía a las mujeres en continua deslocalización, las que como ella (y la india Bárbara) deben ceder el paso para que se erijan las violencias tergiversadas en la idea de progreso y, por qué no, de civilización. Los signos de su tierra recuperan los poderes de las hierbas de la mítica Cólquida, donde hay medicinas capaces de sacarla de una fiebre que, como los choque eléctricos, le calcina el cerebro, como vemos en el extenso fragmento que corresponde al monólogo de apertura de la pieza:

\footnotetext{
${ }^{4}$ En español, "soy del tamaño del amor".
} 
Preciso que me escutem.

Vou ser breve, não vou demorar.

Vivo aqui, foi aqui que chegaram estes pés.

E também outros:

Logo ali, uma vizinha cubana.

Ali, minha vizinha judia.

Ali, aquela paulista.

Ali, a haitiana.

A mulher síria mora naquela direção.

Eis minha vizinhança: aqui os que são de lá. [...]

Toda imigrante que encontro pelas ruas eu cumprimento, compro o que vende, pergunto se quer água.

Penso sempre nas haitianas.

Terra da gente é terra da gente.

Na minha, por exemplo, tratariam essa febre de outra forma.

Preste atenção, toda exilada olha como se tivesse um segredo.

Os homens riscam um quadrado no chão e pronto, nomeiam um país como se desenhassem suas bolsas no solo e depois colocassem nos ombros como suas.

Mentira. Escravizam outros homens pra carregá-las.

Já pisei várias vezes em fronteiras. [...]

Na minha terra, tratariam essa febre com uma simpatia que não existe aquí. [...]

Na minha terra tem fruta que só existe lá.

Ninguém chora com aquela música, EU choro com aquela música.

O sal não é o mesmo em todos os lugares.

Fora que é exaustivo ter que contar a sua história toda vez que.

Alguém me pergunta de onde eu vim e meu olho se enche.

Aqui, sempre me perguntam de onde eu vim, como que pra me lembrar.

A paulista que mora ali só me pergunta isso. 
Penso sempre nas hidrelétricas dando fim às cidades. Na lama. Terra da gente é terra da gente. [...]

Vocês escutaram tudo que eu disse até aqui?

(PASSÔ, 2017, p. 23-27)

Al evocar el amor como parte de sí misma, la Medea de Passô es solidaria con la soledad de la mujer judía; sufre con la incomprensión lingüística y el embarazo de la mujer siria, a quien le propone el aborto; comparte los secretos de la mujer cubana y no se permite interactuar con los prejuicios de la mujer paulista. Al público solo se le permite conocerlas a través del monologo del personaje, así como a las hijas mujeres y a un Jasón que, como una constante desde los mitos y la tragedia de Eurípides, debe su poder a Medea y se presenta a partir de su caída moral.

El tema del racismo, como parte de su carácter como una portademanda, se inserta en la relación de Jasón y su actual compañera, la nueva intendente de la ciudad, una mujer negra con quién Medea hipotéticamente dialoga, pidiéndole perdón por no acordarse de un día haberla empleado en su casa como doméstica. En ese punto, Passô como

\footnotetext{
${ }^{5}$ En español: "Necesito que me escuchen./ Voy a ser breve, no voy a tardar./ Vivo acá, fue acá que llegaron estos pies./ Y también otros:/ Bien allí, una vecina cubana./ Allí, mi vecina judía./ Allí, aquella paulista./ Allí, la haitiana./ La mujer siria vive en aquel lado./ Esta es mi vecindad: acá los que son de allá. [...]/A toda inmigrante que encuentro por las calles, saludo,/ compro lo que vende, pregunto si quiere agua./ Pienso siempre en las haitianas./ Nuestra tierra es nuestra tierra./ En la mía, por ejemplo, tratarían esa fiebre de otra manera./ Prestá atención, toda exiliada mira como si tuviera un secreto./ Los hombres trazan un cuadrado en el suelo y listo, nombran un país como si dibujaran sus bolsas en el piso y después se las pusieran en las espaldas como suyas./ Mentira. Esclavizan a otros hombres para cargarlas./ Ya pisé inúmeras veces las fronteras.[...]/ En mi tierra, tratarían esa fiebre con una sanación que no/ existe acá. [...]/ En mi tierra hay fruta que sólo existe allá./ Nadie llora con aquella canción, YO lloro con aquella canción./ La sal no es la misma en todas partes./ Además de que es agotador tener que contar su historia siempre que./ Alguien me pregunta de donde vine y mi ojo se llena./ Acá, siempre me preguntan de donde vine, como para hacerme recordar./ La paulista que vive allí solo me pregunta eso./ Pienso siempre en las hidroeléctricas poniendo un fin a las ciudades. En el barro./ Nuestra tierra es nuestra tierra. [...]/ Ustedes escucharon todo lo que dije hasta acá?"
} 
escritora negra reivindica en su proyecto la importancia de hablar del racismo en un país maculado por el mito de la democracia racial, que más impide el diálogo franco y abierto que propiamente favorece al reconocimiento de derechos en un sistema simbólico donde las fuerzas hegemónicas aún son de los blancos. Bárbaras, la Medea que no es de ahí y la mujer negra tienen sus fronteras inscritas en el espacio geográfico y en el color de la piel. Pese a eso, la fecha de publicación del texto es un dato bastante relevante si se lo compara con los años siguientes de nuestro país. Publicada en el 2016, el país inhóspito desde donde Medea nos habla todavía es un escenario donde la mujer negra puede tomar un lugar de reconocimiento en el gobierno. Posiblemente, teniendo en cuenta el poder de porta-demanda del personaje, con el brutal asesinato de la concejala del Río de Janeiro, Marielle Franco, el 14 de marzo de 2018, el cierre de la tragedia contemporánea escrita por Passô apuntaría a ese hecho hediondo que, al intentar callar a Marielle, se dispuso a ser una amenaza a todas las mujeres de Brasil, sobre todo, a la voz de la mujer negra, reafirmando que sus cuerpos históricamente están a disposición de un estado que plantea su perversa civilización desde la barbarie.

Como cierre posible de un legado prohibido en lo referente a los derechos de las mujeres, esa Medea dispara su ametralladora hacia el público, donde se proyecta la presencia de sus hijas, todas mujeres que, según ella, están condenadas al encuentro con un Jasón cualquiera, otro dueño de sus cuerpos, otro hombre autorizado al abandono como práctica. La muerte misericordiosa pone un punto final a ese cuerpo que, desde Eurípides, sirve de mote para hablar de lo que persiste en el silencio o en la voz del sujeto incómodo. Es el fin del destino deinós.

Sea como una mujer de tierra bárbara o como la india bárbara; sea como la madre y su crimen bárbaro en Olimar o en un país donde la barbarie asume el sinónimo de futuro, las mujeres desvelan las violencias a las que están sometidas. Escucharlas o no, además de un deseo, puede traducir el deber del aquel civilizado cuyo reconocimiento de humanidad de que nos habla Todorov hace parte de su encuentro con los otros.

En las fronteras que nos unen simbólicamente desde la Cólquida, nuestro sueño de herencia quizá sea lo más simple: reivindicar, desde 
un cuerpo respetado por esos otros, la vida que debe y puede haber en todas las mujeres. Por qué hablar de Medea, además de una pregunta, traduce nuestra urgencia. Su carácter fuerte y su crimen imperdonable revisitados en otros tiempos y espacios, por medio de nuevas voces y exigencias de reconocimiento, ponen en escena un teatro crítico y un discurso atento al género. Desde la ficción, la maternidad vuelve con su potencia transgresora: en la escrita dramatúrgica de tres mujeres, Medea trae en si la cicatriz bárbara, exponiéndola como marca de las violencias a que las mujeres estamos sometidas en la historia. Los filicidios sin el trazo de la venganza traducen lo que puede haber de más primitivo en los discursos acerca de la maternidad: la protección. Contradictoriamente, es matando a los herederos de una identidad desautorizada en la narrativa oficial que cada una, a su manera, amplifica la voz femenina y deja libre el escenario para que la historia sea suya, de los suyos y, por que no, de nosotras.

\section{Referencias}

BADINTER, E. Um amor conquistado. O mito do amor materno. Tradução de Waltensir Dutra. Rio de Janeiro: Nova Fronteira, 1985.

BADINTER, E. O conflito: a mulher e a mãe. Tradução de Vera Lucia dos Reis. Rio de Janeiro: Record, 2011.

BOURDIEU, P. O poder simbólico. Tradução de Fernando Tomaz. Rio de Janeiro: Bertrand Brasil S.A, 1989.

CURESES, D. La frontera. Buenos Aires: Argentores, 1960.

EURÍPIDES. Medeia. Tradução do grupo Trupersa e coordenação de Tereza Virgínia Ribeiro Barbosa. São Paulo: Ateliê Editorial, 2013.

EURÍPIDES. Tragedias I. Edición de Juan Antonio López Férez. Madrid: Ediciones Cátedra, 2010.

JASON, T. A história das línguas: uma introdução. Traducão de Marcos Bagno. São Paulo: Parábola, 2015. 
LABRAGA, M. Sobre el texto y la puesta. Disponible en: <http:// marianapercovich8.blogspot.com/2010/03/sobre-el-texto-y-la-puesta. html . Visitado el: 07 mayo 2018.

MITCHELL, L. Panhellenism and the Barbarian in Archaic and Classical Greece. Swansea: The Classical Press of Wales, 2007.

PASSÔ, G. Mata teu pai. Río de Janeiro: Cobogó, 2017.

PERCOVICH, M. Medea del Olimar. Montevideo, 2009. Edición de la autora.

PERCOVICH, M. Presentación del proyecto. Disponible en: <http:// marianapercovich8.blogspot.com/2010/03/presentacion-del-proyecto. html>. Visitado el: 07 mayo 2018.

POCIÑA, A.; LÓPEZ, A. Otras Medeas. Nuevas aportaciones al estudio literario de Medea. Granada: Editorial Universidad de Granada, 2007.

SAID, E. Cultura e imperialismo. Tradução de Denise Bottmann. São Paulo: Companhia das Letras, 1995.

SARMIENTO, D. F. Facundo. Buenos Aires: Eudeba, 1999.

SPIVAK, G. Quem reivindica alteridade? In: HOLLANDA, H. B. de (Org.). Tendências e impasses: o feminismo como crítica da cultura. Rio de Janeiro: Rocco, 1994. p. 187-205.

SPIVAK, G. En otras palabras, en otros mundos. Ensayos sobre política cultural. Traducción de Alcira Bixio. Buenos Aires: Paidós, 2013.

TODOROV, T. El miedo a los bárbaros. Traducción de Noemí Sobregués. Barcelona: Galaxia Gutenberg, 2014.

Enviado em: 30 de abril de 2018. Aprovado em: 18 de junho de 2018. 